LICENÇA CC BY:

Artigo distribuído sob os termos

Creative Commons, permite uso e distribuição irrestrita em qualquer meio desde que o autor credite a fonte original.

\section{OS CONCEITOS DE INTELIGÊNCIA E DE DEFICIÊNCIA INTELECTUAL: AS MESMAS ORIGENS?}

THE CONCEPTS OF INTELLIGENCE AND INTELLECTUAL DISABILITY: THE SAME ORIGINS?

LOS CONCEPTOS DE INTELIGENCIA Y DISCAPACIDAD INTELECTUAL: LOS MISMOS ORÍGENES?

Andressa Mafezoni Caetano ${ }^{1}$

Márcia Denise Pletsch ${ }^{2}$

${ }^{1}$ Doutora em Educação pela UFES. Docente do Programa de Mestrado Profissional em Educação da Universidade Federal do Espírito Santo (UFES),

Vitória, ES, Brasil.

${ }^{2}$ Doutora em Educação pela UERJ. Docente do Programa de PósGraduação em Educação, Contextos Contemporâneos e Demandas Populares da Universidade Federal Rural do Rio de Janeiro (UFRRJ), Nova Iguaçu, RJ, Brasil.

Resumo: Neste artigo discutem-se as origens dos conceitos de inteligência e de deficiência intelectual a partir do contexto europeu e suas influências no cenário escolar brasileiro. Trata-se uma pesquisa bibliográfica com base nos estudos de Alfred Binet sobre a medida de inteligência e "anormalidade" em diálogo com a literatura científica contemporânea. A partir das análises realizadas, evidenciamos a influência do debate europeu na Educação Especial brasileira. Como considerações finais, mostramos que esses conceitos têm as mesmas origens e foram forjados no contexto de uma ciência médico-psicológica, justificada por um ideário republicano como "solução" dos problemas educacionais brasileiros da época.

Palavras-chave: Deficiência intelectual; Inteligência, Educação especial.

Abstract: In this paper, it is discussed the origins of the concepts of intelligence and intellectual disability from the European context and its influences in the Brazilian school scene. It is a bibliographical research based on the studies of Alfred Binet on the measurement of intelligence and "abnormality" in dialogue with the contemporary scientific literature. From the analysis carried out, we have highlighted the influence of the European context on the Brazilian Special Education. It has also been shown that these concepts have the same origins and were forged in the context of a medicalpsychological science, justified by a republican ideology as a "solution" of the Brazilian educational problems of that time.

Keywords: Intellectual disability; Intelligence; Special Education. 
Resumen: En este artículo se discuten los orígenes de los conceptos de inteligencia y discapacidad intelectual a partir del contexto europeo y sus influencias en el escenario escolar brasileño. Tratase de una investigación bibliográfica basada en los estudios de Alfred Binet sobre la medida de inteligencia y "anormalidad", en diálogo con la literatura científica contemporánea. A partir de los análisis realizados, evidenciamos la influencia de la coyuntura europea en la Educación Especial brasileña. Mostramos que esos conceptos tienen los mismos orígenes y fueron forjados en el contexto de una ciencia médico-psicológica, justificada por un ideario republicano como "solución" de los problemas educativos brasileños de la época.

Palabras clave: Discapacidad intelectual; Inteligencia, Educación especial.

\section{Introdução}

Como se vê, os termos brotam, fáceis, e suficientemente vagos para serem intercambiáveis sem maiores escrúpulos semânticos ou metodológicos (PESSOTTI, 1984).

Os conceitos de inteligência e deficiência intelectual ${ }^{2}$ são complexos em sua essência e têm sido utilizados historicamente na área da Educação Especial, sem muitos questionamentos sobre suas origens e significados. Para refletirmos sobre a inteligência e a deficiência intelectual, é preciso vislumbrar que esses conceitos têm sido construídos e reconstruídos de diferentes maneiras, por meio de modelos socioculturais em momentos históricos específicos, e que ainda na atualidade, não há consenso entre as áreas acadêmicas sobre eles. Por isso, é necessário observarmos suas bases e indagá-las, a fim de compreendermos os seus usos e as suas implicações no processo de escolarização de alunos com deficiência intelectual na contemporaneidade.

Tomamos como ponto de partida a sociedade que é o lócus privilegiado das relações sociais, e, tendo em vista que ela é representada pelas instituições sociais, elegemos a escola para pensar sobre a construção e apreensão desses conceitos, uma vez que, ela lida com uma diversidade de sujeitos e que tem elegido os mais e menos inteligentes, os denominados "normais e anormais", os "aptos e inaptos" por meio de olhares e práticas homogêneas.

Nessa perspectiva, o objetivamos neste artigo apresentar as origens dos conceitos de inteligência e deficiência intelectual no âmbito escolar a partir do contexto europeu, assim como problematizar as suas influências e as implicações no cenário escolar brasileiro. É importante esclarecer que este é um assunto extenso e, para fins deste artigo, consideraremos a construção destes conceitos tomando como pressuposto a perspectiva de Alfred Binet sobre inteligência. Nosso foco, não será descrever os procedimentos relativos a medidas de inteligência/deficiência e normalidade/ anormalidade, mas compreender como a perspectiva de Binet costurou esses conceitos e como eles foram incorporados pela cultura educacional europeia e, posteriormente, no contexto brasileiro, por meio de uma suposta educação sob medida. 
Em termos metodológicos seguimos os pressupostos da pesquisa qualitativa do tipo bibliográfico, conforme discutido por Lima e Mioto (2007) e Andrade (2010). Para tal, realizamos uma pesquisa focando descritores como inteligência, anormalidade, deficiência mental e Alfred Binet. Os achados foram analisados a luz da literatura cientifica contemporânea envolvendo a temática. A partir da análise qualitativa do material selecionado organizamos nossas discussões em dois eixos, a saber: a) A origem do conceito de inteligência e sua relação com o conceito de deficiência mental/intelectual; e b) $O$ contexto europeu e sua influência na educação brasileira.

\section{A origem do conceito de inteligência e sua relação com o conceito de deficiência intelectual}

Consideramos que cada sociedade em seu tempo próprio, além de demandar da escola, a sistematização dos saberes produzidos em diferentes culturas, também solicitou dos indivíduos um papel social que atendesse aos seus interesses sóciopolíticos-econômicos e ideológicos, fossem individuais ou coletivos, cobrando de seus usuários o retorno de que deveriam caber dentro das teorias formuladas em cada momento histórico.

Essas teorias, nascidas das ideologias da classe dominante, foram validadas em nome da "ciência", que por meio de procedimentos e métodos de análise científicos, hierarquizaram as capacidades dos indivíduos, legitimando uma ordem social que, desde então, até os dias atuais, subjuga as possibilidades de aprendizagem e consequentemente os papeis sociais. Analisando, sob esse viés, podemos colocar em evidência que a inteligência, têm sido entre os diferentes grupos socioculturais, entendida por meio de atributos cognitivos, sociais e comportamentais que podem passar pela necessidade de adaptação em um determinado ambiente e contexto.

Levantando essa premissa, é de valia, iniciar essa reflexão a partir da Teoria da Evolução das Espécies de Charles Darwin (1858), que contribuiu sobremaneira para a construção de um novo conceito de inteligência ${ }^{3}$ no final do século XIX e início do século XX. Por meio de noções como adaptação e hereditariedade, ao colocar o Homem na escala animal e admitir explicitamente a partilha de ancestrais com outras espécies, Darwin reconhece à inteligência humana características que, não constituindo mais do que uma extensão das que se encontram noutras espécies, lhe são únicas, funcionalmente significativas e, por consequência, de valor adaptativo (Afonso, 2007, pag. 20).

Esse olhar sobre a natureza humana, abriu a possibilidade de compreender o homem por meio de atributos biológicos, validá-los e legitimá-los de acordo com os valores vigentes naquela época. Nesse limiar, Francis Galton (1822-1911), influenciado 
pela Teoria da Evolução das Espécies, da fisiologia e da estatística, e, tendo por base a noção de adaptação, propõe a partir de seus estudos, um novo conceito de inteligência. Essa nova proposta preconizava a medida da variação na capacidade mental humana, o que mais tarde culminaria na elaboração do método da análise fatorial, que seria aplicado na validação dos testes para a medida da inteligência. Ele almejava que por meio da medida dos processos sensoriais e tempo de reação, conseguir chegar a uma estimativa do nível intelectual dos sujeitos.

Gould (1999 p. 67), evidencia que Francis Galton foi o pioneiro da estatística moderna, que acreditava que, com suficiente empenho e engenhosidade, qualquer coisa podia ser medida, e que essa medida constituiria o critério básico de um estudo científico. Aponta que por meio da utilização da quantificação tinha a firme conviç̧ão de que quase tudo que podia medir tinha um caráter hereditário. A principal obra de Galton sobre o caráter hereditário da inteligência (Hereditary Genius, 1869) inclui a antropometria entre seus critérios, mas seu interesse pela medição dos crânios e dos corpos atingiu o nível máximo quando instalou um laboratório na Exposição Internacional de 1884 (Gould, 1999, p. 68).

A literatura aponta (ALMEIDA, 2002; GOULD, 1999) que o trabalho realizado por Francis Galton, inaugura a primeira abordagem da inteligência humana no nascedouro de uma psicologia científica, que viria a ser conhecida por Psicologia diferencial. É importante anotar que esta não será a única corrente de medida e avaliação do que se convencionou como inteligência. Ainda, de acordo com Almeida (2002) os primeiros estudos sobre a inteligência, buscavam a sua essência e não as várias aptidões que a poderiam diferenciar e, que este movimento assentado na unicidade da inteligência teve, no entanto, duas formas diferentes de expressão. Uma delas se configura na defesa da integração de funções cognitivas diversas num potencial ou quociente de inteligência (teoria da inteligência compósita), e outra na proposta de um elemento básico e comum a todas as atividades cognitivas (teoria do fator geral ou $g$ ). Ainda sobre este assunto Almeida sinaliza que:

\footnotetext{
Estas concepções datam do final do século XIX, constituindo Sir Francis Galton um nome de referência ao conceber a capacidade intelectual como uma manifestação das capacidades mais básicas de discriminações sensoriais. A capacidade intelectual do sujeito refletiria a sua destreza e o grau de complexidade associativa nessas funções básicas, originando, então, a utilização de provas sensoriais e motoras na avaliação da inteligência. Galton, neste enquadramento teórico, construiu uma escala métrica, cujos testes avaliavam traços físicos, acuidade sensorial, força muscular e tempos de reação, entre outras capacidades sensório-motoras simples (ALMEIDA, 2002, p. 2).
}

A psicologia das diferenças individuais foi construída com base nas concepções das ciências naturais e nos métodos das ciências exatas para assegurar o status de ciência no decorrer do século XIX, que por meio da utilização do método experimental, vinculouse ao evolucionismo e a fisiologia. Para Patto (2000), a psicologia diferencial agregou os conceitos de variação, seleção e adaptação, utilizando-os no estudo das capacidades mentais individuais. Nesse contexto, a fisiologia se localizou no bojo de pesquisas 
realizadas nos laboratórios de Psicologia, coexistindo com experimentos relativos a discriminação sensorial, processos fisiológicos e psicológicos. Entende-se que naquele momento a fisiologia estava próxima a teoria evolucionista, dado que esteve relacionada à concepção de "sobrevivência dos mais aptos". Dessa maneira, Francis Galton chegaria ao seu propósito, que era o de mensurar os processos sensoriais e o tempo de reação para estimar o "nível intelectual" dos sujeitos.

É a partir destes pressupostos que, no final do século XIX e início do século XX, na França, conforme Ferreira (2016) a prerrogativa de medir a inteligência acompanha o movimento de retirar as crianças dos asilos do hospital de Bicêtre em Paris, sob os cuidados do médico alienista ${ }^{4}$ Desirée-Magloire Bourneville, para escolarizá-las no contexto da Educação Nacional da França. Nessa linha temporal, não é menos importante dizer que Pessotti (1984, pag. 41) quando analisa o contexto histórico em relação ao Selvagem de Aveyron e aos cuidados médico-pedagógicos de Jean Marc Itard ao final dos anos 1800, explica que a medicina moral ${ }^{5}$ era a designação genérica para as atividades da psicologia clínica e da psiquiatria, que se organizariam como profissões muito mais tarde.

Nessa esteira, o autor argumenta que a deficiência era um problema médico, e, portanto, passível de tratamento, ou seja, caberia ao médico alterar os hábitos ou maus hábitos pelo exercício de uma medicina moral. Tal medicina, deveria corrigir ou introduzir outras noções de comportamentos, modificando-os de maneira que os sujeitos acometidos por ela, produzissem/reproduzissem comportamentos desejáveis em detrimento dos indesejáveis, referentes aos preceitos morais da época. De todo modo, naquele momento, não havia um movimento ou tradição de ensino para os "idiotas" categorizados em imbecis, amentes ou oligofrênicos ainda porque, tradicionalmente desde Parecelso e Cardano, amência e demência eram processos de patologia cerebral e, portanto, assunto privativo do médico (Pessotti, 1984. p. 42).

De acordo com Menecier (2003), nesse cenário social, há uma importante evolução da higiene e da microbiologia ao final do século XIX, o que se configurava como uma das condições propícias ao crescente prestígio da medicina e sua ascendência sobre a sociedade. Os médicos passam a ser vistos politicamente como propensos a fornecer respostas eficazes aos problemas sociais impostos pela industrialização e aos fenômenos resultantes da urbanização.

Aliado a essa concepção, a medicina avançava na compreensão da noção de sujeito psíquico, o que para Pessotti (1984, p. 37) provocaram novas classificações da loucura, evidenciadas por Philippe Pinel no célebre Traité médico-philosophique sur l'aliénation mentale, cuja primeira publicação data de 1801, recebendo a deficiência mental uma atenção apenas secundária, mesmo que ele tenha colocado o problema da idiotia no domínio da patologia cerebral.

Diante dos saberes clínicos da época, a Psiquiatria investiu na tentativa de explicar os fenômenos psíquicos, e que, nesse momento, a debilidade mental era traduzida em 
uma categoria e caracterizada como uma doença congênita reversível e recuperável, a partir do entendimento de que um trabalho terapêutico próprio, reverteria o aspecto degenerativo causado pelo déficit intelectual. Esse olhar recaía, segundo Santiago (2004):

\begin{abstract}
Na perspectiva de um tratamento dos débeis, segundo uma ótica puramente ortopédica da falta de inteligência e de tratamento moral da inópia desses sujeitos, pela via de uma reeducação pedagógica. A inadaptação intelectual e o critério da educabilidade do débil passam a ser uma contribuição semiológica e clínica que o campo médico da psiquiatria empresta a educação. [...] no âmbito da educação, a debilidade adquire de forma definitiva, a qualificação de mental. Assim adjetivada essa noção de "debilidade mental" impõe-se, rapidamente, como uma forma de diagnóstico do aluno que apresenta distúrbios de aprendizagem e vai não somente designar o que é da esfera específica do mental, mas também apontar os entraves do desempenho escolar do aluno. Em consequência, os impasses do escolar na sua relação com o aprendizado da leitura e da escrita começam a adquirir valor de índice somático de debilidade mental. Por esse processo, as classificações das patologias da inteligência permanecem associadas, em grande parte, ao fator essencialmente fenomênico da capacidade de adaptação do escolar aos padrões vigentes de escolarização (p.62).
\end{abstract}

Realizado o encontro entre a Medicina/Psiquiatria e a Psicologia, e a partir de sua validade científica, foram tecidos na educação os conceitos de inteligência e deficiência mental/intelectual, uma vez que a categorização de debilidade mental foi juntada a instrumentos de verificação do desempenho escolar dos alunos, em um primeiro momento nas escolas públicas francesas.

Essa medida foi ancorada na ideia de "adaptação" escolar tão criticada na atualidade, colando os pressupostos de inteligência e deficiência. Além disso, a deficiência mental enquanto parte da categoria de debilidade mental era relacionada ao que se chamava de fraqueza e insuficiência das faculdades mentais. Esses entendimentos foram transformados em procedimentos de medida e avaliação da inteligência, e, considerados científicos, conferindo um valor objetivável e transmissível de verdade nas investigações de Alfred Binet e seus colaboradores. Assim, nasceu a ideia de anormalidade versus normalidade.

A ideia contida nesses conceitos assumiu, para além do caráter ideológico, o higiênico, permeado por aspectos políticos e econômicos. Deste modo, no entendimento de Ferreira (2016, pag. 36) foi no entrecruzamento dos discursos pedagógico, psicológico, higiênico e disciplinar que se situava a concepção de anormalidade desenvolvida por Alfred Binet e seus colaboradores. Vejamos em suas palavras:

Associado à concepção de anormalidade, está seu empenho na criação de um "método científico" válido para revelar as crianças anormais no ensino primário francês. Logicamente, seu discurso está intimamente ligado e imbricado com a educabilidade das crianças consideradas anormais que, para além dos muros hospitalares, ganharam "visibilidade científica" e passaram a ser denominadas "anormais da escola" (FERREIRA, 2016, p. 36).

Na busca de espaço e para a implantação de suas ideias na instrução pública francesa Alfred Binet, iniciou críticas rigorosas ao trabalho do médico alienista DesiréeMagloire Bourneville e, sobretudo em relação às despesas aos cofres públicos geradas pela reforma do pavilhão infantil no hospital de Bicêtre. A partir da reforma, e, por uma questão de organização, de acordo Yves (2007), as crianças foram separadas em três grupos. No primeiro, as crianças mais seriamente consideradas deficientes, 
consideradas inválidas. No segundo, as crianças com os mesmos transtornos, consideradas válidas e, o terceiro composto pelas crianças menos afetadas, aquelas, cuja deficiência mental seria mais leve. O primeiro grupo, visto como incapacitado, foi beneficiado com cuidados de higiene e estavam no setor médico. O segundo grupo, estaria na pequena escola que ofereceria uma educação motora e sensorial, enquanto era chamada de grande escola, atenderia o terceiro grupo na qual, se familiarizariam com o ensino primário. Os níveis eram pensados de acordo com as aptidões físicas e intelectuais, e o assento nesses grupos não eram definitivos, ou seja, poderiam migrar de grupo dependendo de seu desenvolvimento e não de sua patologia, ao passo que o alienista defendia que o idiota era educável.

Conforme Ferreira (2016), com esse olhar, Bourneville presta atenção à constante articulação que deveria existir entre o cuidado e a escola. Ele considerava que os cuidadores e educadores deveriam ter uma visão total do tratamento e educação das crianças, postulando que os profissionais que trabalhavam com as crianças de Bicêtre deveriam receber instruções de enfermagem, criando a base do seu chamado método "médico-pedagógico".

Na contramão da perspectiva de Bourneville, no entendimento de Yves (2007), Binet foi o promotor incansável de uma "psicologia experimental", científica e "positiva" que apoiava para garantir o reconhecimento e o desenvolvimento das questões levantadas pela escolaridade obrigatória, promulgada pelas leis de Ferry de 1882, que garantia a educação pública e gratuita para crianças de 6 a 14 anos. Nesse sentido, a escola era o lugar para que fossem disseminados os ideais burgueses, que ofereciam civilidade, mas o mesmo tempo, interviam no modo de vida das classes populares. Com objetivos demarcados,

Binet não demorou a ver, na experimentação instrumental, mesmo em processos aparentemente elementares, um pretexto para aprofundar a complexidade da mente. Então ele precisava de um ambiente mais vivo, que ele logo encontrou nas escolas, especialmente na Rue Grange-aux-Belles. Em 1899, dois eventos acelerarão esse processo: o encontro com Theodore Simon e a criação de Ferdinand Buisson, da Sociedade Livre para o Estudo Psicológico da Criança, que Binet se tornará presidente a partir de 1902 (OUVRIER-BONNAZ, 2011, p.138).

Incialmente, Binet não fora bem visto na Sociedade, na qual suas ideias não eram ouvidas, ao passo que também existiam divergências teórico-metodológicas com as quais ele foi tentando lidar, mas ao mesmo tempo não deixando de investir em seus trabalhos com a intenção de inserir suas ideias no campo da Pedagogia. Quando Binet se tornou diretor da Sociedade em 1902, propôs outras formas de trabalho e entre elas, comissões que cuidariam de assuntos diversos. Ferreira (2016), p. 65, esclarece que entre essas comissões, encontravam-se aquelas destinada ao estudo das crianças anormais, devido ao fato de que o Ministério da Instrução Pública desejava diagnosticar as crianças que não tinham sucesso de aprendizagem da leitura e da escrita. 
No texto Méthodes nouvelles pour le diagnostic du niveau intellectuel des anormaux, em 1904, Binet e Simon atestam que é necessário compreender qual o significado desta palavra tão vaga abrangente: "a inteligência". No decorrer do mesmo texto, afirmam que quase todos os fenômenos dos quais a psicologia se ocupa são fenômenos da inteligência, sendo que mesmo a sensação e a percepção seriam consideradas manifestações intelectuais como o raciocínio. Não obstante, declaram que existiria uma faculdade fundamental na inteligência, que para a vida prática é muito importante, que é a capacidade de julgamento, ou seja, o bom senso, a praticidade, a iniciativa, a habilidade de adaptação.

Nesse movimento, Binet iniciou seus trabalhos nas escolas com o auxílio de Théodore Simon, inicialmente realizando estudos e pesquisas por meio de questionários que culminaram na escala métrica de inteligência, na busca de definir a infância anormal. Em análise do livro Les enfants anormaux, Ferreira (2016), esclarece que a preocupação inicial de Binet, se ancorava na definição da anormalidade e em enumerar seus caracteres intelectuais morais e escolares. Importava-lhe muito apresentar uma definição bem demarcada do conceito, pois acreditava ser esta noção a base da "organização das escolas e, sobretudo, da pedagogia especial". Ferreira assim descreve as crenças de Binet:

\begin{abstract}
Nas suas proposições, Alfred Binet vai eliminar os cegos e os surdos, alegando a especialidade destas categorias. Elimina também os considerados mais gravemente atingidos, que exigem um tratamento médico incessante. Para estes indicará os hospitais, os hospícios e os asilos. Consequentemente, suas proposições vão privilegiar crianças que continuavam a frequentar os estabelecimentos primários (que, em razão da obrigatoriedade escolar, não lhes podem fechar as portas), mas não aproveitavam o ensino aí ministrado. Este "não conseguir aprender" vai gerar as queixas dos professores. Queixas que Alfred Binet atribui a debilidade mental de seus alunos, considerados providos de inteligência e, portanto, incapazes de se beneficiar de um trabalho comum com os normais (FERREIRA, 2016, p. 69).
\end{abstract}

No mesmo livro Les enfants anormaux (pág. 22), verificamos que Binet defendia que o primeiro dever do educador era levar em consideração as faculdades já desenvolvidas das crianças e que, o trabalho dos professores era difícil e ingrato e que ele estaria errado em não aproveitar a colaboração da natureza. Podemos inferir que Binet transferia a responsabilidade de um ensino especial aos professores. Igualmente, defendia que deveria dar-se preferência à instrução dos anormais, que tomariam a maior medida de suas habilidades naturais.

$\mathrm{Na}$ escola, se fundiam os conceitos de anormalidade (deficiência) e de inteligência. Para Ferreira (2016) Alfred Binet e Théodore Simon, mesmo exaltando a amplitude do instrumento quanto ao seu largo emprego em que "as mais preciosas aplicações de nossa escala não seriam para o sujeito normal, mas para os graus inferiores da inteligência". Assim, infere-se que os graus inferiores da inteligência, eram aquilo que não cabia dentro da escola, ampliando a necessidade de colocação desses indivíduos no ensino especial. Mesmo que as ideias de Alfred Binet, não tenham sido aceitas na França, por muitos médicos e psicólogos da época, o ensino especial fora implantado, as escalas de inteligência utilizadas, assim como os testes 
mentais e sua divulgação em outros países, inclusive no Brasil, como pode ser visto no tópico a seguir.

\section{O contexto Europeu e sua influência na Educação} brasileira

No Brasil, a primeira metade do século XX, foi determinante para acolher estudos estrangeiros sobre a inteligência, principalmente os franceses, apoiados nas ideias de anormalidade e medida da inteligência de Alfred Binet e seus precursores. Além disso, a maioria das publicações nacionais em relação a anormalidade/ deficiência mental, e consequentemente a escolarização das pessoas que se encontravam nesta classificação, eram oriundas de textos de docentes de clínica neurológica e psiquiátrica das faculdades de Medicina, avalizados por profissionais colaboradores de instituições que, naquele momento eram responsáveis pelo atendimento educacional desses sujeitos.

Nesse período, essas publicações contribuíram para a produção da identidade da criança anormal no Brasil, classificando e construindo muitos significados acerca deste termo, que foram se moldando em sentido amplo. São exemplos dessas classificações estrangeiras de acordo com Lobo (2008, p. 379) que podem ser limitadas ao termo idiotas e ora estendem-no aos mais diversos tipos de "déficit", doença, lesão ou perturbação de qualquer natureza ou graus [...] incluem-se os atrasados pedagógicos, retardados mentais, débeis mentais, os fisicamente débeis, astênicos ou preguiçosos, os paralíticos, os epiléticos, histéricos, imbecis morais, instáveis, retardados instáveis ou mistos, indisciplinados, desequilibrados, as crianças maltratadas viciosas, viciadas, abandonadas e as anomalias transitórias.

Constata-se muitas formas de olhar para a anormalidade, o que denota um tom negativo ao fenômeno, que não se apresenta com clareza nas discussões. Para além de um olhar difuso da anormalidade/deficiência intelectual, a Psicometria, o eugenismo e a higiene mental, ganharam espaço no seio de um ideário que desenvolveria uma educação que deveria elevar o nível da nação brasileira. As ideias eugenistas, pressupunham as diferenças socioculturais traduzidas em desigualdades raciais, enquanto inferioridade inata dos indivíduos. De acordo com Wanderbroock Junior, (2016, p. 108), o caráter profilático do trato com a criança era evidente e o objetivo era o de higienizar para conter [...] para não incorrer em erro, o melhor seria entendelas, testá-las, selecioná-las e preparar as "sadias" para o futuro, enquanto as "doentes" seriam depuradas e confinadas em escolas especiais.

Nesse sentido, de acordo com Lobo (2008) e Ferreira (2016), foi no Rio de Janeiro (1905), que surgiu a primeira iniciativa pedagógica, por parte dos médicos Juliano Moreira e Fernando Figueira, para o tratamento institucional de crianças asiladas: tratava-se do "Pavilhão Bourneville" no hospício da Praia Vermelha. 
Sobre esse movimento, é pertinente perguntar, quais foram os parâmetros usados naquele momento, para a definição de anormalidade/deficiência mental na educação brasileira, ou melhor, nas escolas brasileiras? Entendemos que o principal parâmetro foi a legitimação da Psicologia enquanto ciência, que adentrou o sistema escolar público num momento de crescimento urbano/industrial e, a consequente, necessidade de expansão da escolarização das massas, baseada em um ideário republicano que:

\footnotetext{
Depositou expectativas na Psicologia enquanto ciência aplicada, capaz de solucionar problemas do ensino, como também possibilitar o conhecimento científico de questões psicológicas, como a questão da inteligência. Logo tais conhecimentos demonstrariam sua utilidade na revelação de métodos mais adequados ao ensino, tanto dos normais quanto dos débeis, uma vez que os testes psicológicos proporcionariam mais objetividade na avaliação, no diagnóstico e no prognóstico dos caminhos da educação (FERREIRA, 2016, p. 155).
}

Por meio deste ideário, e da colaboração entre a Psicologia, ancorada na Psicometria e na Medicina, numa perspectiva eugênica e homogênea de sujeito, surgiu um movimento importante, que foi o de implantação de uma Pedagogia Científica que já vinha sendo discutida na Europa, com a instalação do Laboratório de Pedagogia Experimental, no Gabinete de Psicologia e Antropometria Pedagógica, anexo a Escola Normal Secundária de São Paulo. A Pedagogia Científica, teve ingresso em São Paulo por meio de Clemente Quaglio.

De acordo com Monarcha (2007) e Centofanti (2006), Clemente Quaglio defendia a criação de asilos-escola que eram internatos, dotados de gabinetes de antropologia pedagógica e psicologia experimental e de cursos especiais anexos às escolas normais, destinados a formar professores para ensino dos anormais psíquicos ou anormais "verdadeiros". Sobre o tema Monarcha (2007) nos esclarece que foi de Clemente Quaglio, a decisão controversa de aplicar a escala métrica de inteligência de BinetSimon a populações escolares da Capital, sem dúvida, primeira aplicação coletiva desse instrumento, em nosso país, cujos resultados constam no livro $A$ solução do problema pedagógico social da educação da infância anormal de inteligência no Brasil (1913). Assim, é possível inferir que os asilos-escola demandariam a intervenção médica e a formação de professores para o ensino especial dos anormais teria a intervenção psicológica.

Como nos coloca Jannuzzi (2006), Quaglio, em 1917, colocou em dúvida a quantidade de anormais em detrimento de descobertas de casos de anormalidade por parte de professores noviços, que segundo ele, poderiam estar encobrindo e disfarçando a sua incompetência ou falta de dedicação ao ensino. A partir deste levantamento, na escola pública, separando, ou melhor pretendendo apontar nela os deficientes mentais pela escala métrica de inteligência de Binet e Simon, representou uma clivagem "nova" baseada nos critérios de aproveitamento escolar, o que para ele, demonstrava a necessidade urgente de criação de escolas especiais, ou seja, separar os normais dos anormais. Essa perspectiva permaneceu presente no Brasil durante décadas e influenciou fortemente a criação das escolas dos excepcionais nos anos de 1970 no Rio de Janeiro, como apresentado por Scheneider (2003). 
Mas, em meio a esta classificação tão difusa, como reconhecer os anormais nas escolas? Sobre esse questionamento, é importante destacar a problematização trazida por Lobo (2008), que dentre as classificações médico-pedagógicas difundidas na época, argumenta que o grande problema da escola eram os outros, aqueles que num primeiro momento, poderiam passar despercebidos ao olhar do mestre, ou seja, aqueles vistos como intermediários que, misturados nas escolas regulares, espalhavam desordem e a indisciplina e impossibilitavam qualquer trabalho pedagógico.

A partir desta premissa, Quaglio e seus colaboradores se ocupariam dos retardados instáveis, isto é, dos anormais psíquicos verdadeiros, segundo a Classificação de Binet, [...] que devido a uma enfermidade congênita ou aquisita dos centros nervosos, apresentam distúrbios no desenvolvimento intelectual que os tornam incapazes de se adaptarem ao meio em que devem viver regularmente (LOBO, 2008, p. 383). Sob o viés da adaptação, da classificação médico-psicométrica-pedagógica, selava a relação entre anormalidade e perigo social, acrescentando mais um aspecto de medida na tênue classificação entre anormalidade e inteligência.

Com a afirmação da escala métrica para medir a inteligência, ela passou a ser usada como o instrumento pela Psicometria para confirmar a normalidade/anormalidade das crianças a partir de sua origem social. Essa Psicometria emanava os pressupostos eugenistas e segregacionistas, também reconhecidos em Alfred Binet. Nessa perspectiva, por meio da concepção de uma capacidade média dos indivíduos, a anormalidade/ deficiência mental, ganhou estatuto e identidade por meio do movimento de ampliação do sistema público de educação brasileiro.

Essa identidade foi se construindo em meio a ampliação do sistema público de educação, que consoante as discussões de Lobo (2008), havia muito, médicos e educadores que advertiam os poderes públicos para a vantagem econômica de separar os anormais das escolas primárias, havendo o argumento da racionalização e aproveitamento dos normais. Em primeiro lugar, esse argumento se baseava na perda de tempo desprendida pelo professor para ensinar e, que os capazes de progredir eram muito prejudicados. Em segundo lugar, o argumento era o do perigo e do fardo social considerado pesado tanto para seus parentes, como para os poderes públicos. Em terceiro lugar o argumento do desperdício econômico, ou seja, capital gasto com os improdutivos.

Nesse sentido, a ampliação do sistema público de educação e a consequente proposta de universalização do ensino, toma força por meio de reformas educacionais, ancorados principalmente, nas décadas de 1920 e 1930, com a divulgação dos ideais da Escola Nova. Em meio a essa dinâmica republicana, de acordo com Ferreira (2016, p. 109) o professor Lourenço Filho traduziu e prefaciou o livro Os testes para a medida do desenvolvimento da inteligência de Alfred Binet e Théodore Simon em 1929, qualificando a obra como de valor histórico relevante, o qual trouxe mobilidade a divulgação dos testes mentais. Seguem as palavras de Lourenço Filho sobre o livro: 


\begin{abstract}
Sobre o valor histórico, e o da homenagem modesta que a maior divulgação da obra, entre nossos educadores, possa representar, acresce o do conhecimento de um processo de medida psicológica sem aparelhamento complicado, podíamos mesmo dizer, sem aparelhamento algum que habilita todo mestre a tentar a experimentação psycológica, por si só, e a observar por ella, melhormente seus discípulos (LOURENÇO FILHO, pág. 5 e 6, 1929).
\end{abstract}

Como podemos depreender, assim como já dito por Monarcha (2001), o movimento dos testes visava ao aperfeiçoamento das técnicas de diagnose e predição mediante a utilização de provas breves e objetivas na forma de questionários passíveis de aplicação em larga escala. Para um contemporâneo daquela época, os testes permitiam a concretização do chamado "sonho dourado da pedagogia": formação de classes homogêneas, classes especiais de retardados e bem-dotados de inteligência, como sinalizado em vários textos escritos naquele período por Helena Antipoff.

Tendo os testes como pressuposto de medida da inteligência, as diferenças sociais apagavam-se, revelando as diferenças de aprendizagem, justificadas cientificamente conforme a adaptação, maturidade e o desenvolvimento da capacidade de cada um. Esses pressupostos eram usados para classificar os alunos em "imaturos", prováveis "alunos excepcionais" e "maduros" para a aprendizagem e contribuiu para aumentar, sobremaneira, o número de classes especiais nas décadas de 1960 e 1970 (SCHNEIDER, 2003).

Entre muitos estudos empreendidos no Brasil, aquele momento histórico foi marcado por um ideal científico e pelo imaginário da sociedade que, perpassou por questões de ordem econômica, política e ideológica, tendo por base as medidas individuais, por meio da medicina e da experimentação da psicologia enquanto ciência aplicada que se estabeleceu no sistema educacional brasileiro. Dessa maneira, ensinanos Canguilhem (2009) que normalizar, é impor uma exigência a uma existência, a um dado cuja variedade e disparidade se apresentam, em relação à exigência, como um indeterminado hostil, mais ainda do que estranho.

\title{
Algumas considerações
}

A construção do conceito de inteligência em detrimento do de deficiência intelectual tem realizado percursos que vêm levando a uma imprecisão sobre o mesmo. Em grande medida essa imprecisão tem impactado na perspectiva de escolarização destes sujeitos que continuam sendo caracterizados a partir de pressupostos biológicos focalizados nas características do laudo, em detrimento de concepções sociais e de direitos (BUENO, 2009; BRIDI, 2011; CARNEIRO, 2017; PLETSCH E PAIVA, 2018). Atrelada a esse movimento, insere-se a medida da inteligência aliada a teorias psicométricas que, por sua vez, eugenistas têm confluência com o conceito de deficiência intelectual, desenhando um sujeito inadequado ao ensino regular, não somente em épocas passadas, mas ainda perdurando a ideia de os sujeitos com deficiência intelectual, 
não estarem "adaptados" à escola vigente. Em outras palavras, entendemos que esses conceitos têm as mesmas raízes, ou seja, estão emparelhados, visto que se encorparam no seio da medicina e da psicologia, sendo agregados à educação em um momento de desenvolvimento dessas ciências e de mudanças sociais.

Diante disso, é importante ressaltar que a deficiência intelectual ainda tem se colocado na escola como um paradoxo, inclusive pelo fato de que, quando não dispomos em mãos de um diagnóstico médico e quantitativo, não conseguimos materializá-la. Nesse sentido, reforçamos uma sociedade que privilegia o desempenho individual, em que cada indivíduo vale o que produz, e, por isso, é importante que se discuta e compreenda as origens e os significados que conceitos vem adquirindo ao longo do tempo. Em meio a esta necessidade, ainda na atualidade, pelo menos no campo escolar, a pouca discussão terminológica e conceitual, os limites frágeis e tênues entre as condições de vida, os processos de escolarização e a constituição do sujeito tornam obscuros e confusos os processos de identificação desses alunos no ambiente escolar (BRIDI, 2015).

A necessidade indevida da escola em apontar os mais e menos inteligentes, vem se constituindo por meio de desconhecimento e dilemas. Um deles é não compreender a educação a partir do que é próprio da educação, sem desconsiderar aqui a importância da interação entre as áreas que compõe a escolarização de alunos com deficiência intelectual. O desentendimento destes conceitos pela escola, tem resultado em conflitos subsidiados por uma denominação estatística e clínica, ao contrário do fazer pedagógico que é baseado no desenvolvimento do aluno.

Tomando essa perspectiva como pano de fundo, concluímos sinalizando que é preciso estar atento ao fato de que os conceitos de deficiência intelectual e inteligência são insólitos, compreendendo que eles têm em nosso ponto de vista, as mesmas origens: foram forjados a partir de uma ciência médico-psicológica, aceitos pela escola, em um momento sócio-político-econômico em que havia a necessidade de justificar o ideário republicano, em que o papel da psicologia, em grande medida, era o de resolver os problemas educacionais e, para a medicina era imputado a higienização do povo brasileiro. Foi nesse movimento multifacetado na escola que se legitimaram os interesses da "ciência" dominante, os quais foram incorporados e validados por uma Educação Especial baseada em uma educação sob medida.

\section{Referências}

ALMEIDA, L. S. As aptidões na definição e avaliação da inteligência: o concurso da análise fatorial. Rev. Paidéia, Lisboa, v.23, p. 5-17, 2002.

AFONSO, M, J. Paradigmas diferencial e sistémico de investigação da inteligência humana: perspectiva sobre o lugar e o sentido do construto. 2007. 659f. Tese (Doutorado em Educação) 
- Programa de Pós-Graduação em Educação, Faculdade de Psicologia e Ciências da Educação. Universidade de Lisboa, Lisboa, 2007.

ANDRADE. M. M. Introdução a metodologia do trabalho científico. 10 ed. São Paulo: Atlas, 2010.

BINET. A. Les enfants anormaux. Paris : Librarie Armande Colin, 1907.

BINET A.; SIMON T. (1904). Méthodes nouvelles pour le diagnostic du niveau intellectuel des anormaux. In L'année psychologique. (Vol. 11. pp. 191-244).

BINET, A.; SIMON, T. Testes para medida do desenvolvimento da inteligência nas crianças. Tradução de Lourenço Filho. São Paulo: Editora Companhia Melhoramentos, 1929.

BRIDI, F. R. S. Processos de identificação e diagnóstico: os alunos com deficiência mental no contexto do atendimento educacional especializado. 2011. 210 f. Tese (Doutorado em Educação) - Programa de Pós-Graduação em Educação, Faculdade de Educação, Universidade Federal do Rio Grande do Sul, Porto Alegre, 2011.

BUENO. J. G. S. A produção social da identidade do anormal. In: FREITAS, Marcos Cezar de (Org.). História social da infância no Brasil. 7. ed. São Paulo: Cortez, 2009.

CARNEIRO, M. S. C. Contribuições da abordagem histórico-cultural para a compreensão da deficiência intelectual como produção social: In: CAIADO, K. R. M.; BAPTISTA, C. R; JESUS; D. M.; (Org.). Deficiência mental e deficiência intelectual em debate. Uberlândia: Navegando Publicações, 2017.

CENTOFANTI. R. Os Laboratórios de Psicologia nas escolas normais de São Paulo: o despertar da Psicometria. Revista Psicologia educacional. São Paulo, n. 22, 2006.

FERREIRA. C.M.R.J. Às sombras das escalas: um estudo sobre a concepção de anormalidade em Alfred Binet. Belo Horizonte: Fino Traço, 2016.

GATEAUX-MENNECIER, J. L'oeuvre médico-sociale de Bourneville. Histoire des sciences médicales, tome XXXVII, $n^{\circ} 1,2003$.

GOULD, S. J. A falsa medida do homem. São Paulo. 2. Ed. Martins fontes: 1999.

JANUZZI, G. S. de M. A educação do deficiente no Brasil: dos primórdios ao início do século XXI. 2 ed. Campinas; Autores Associados: 2006.

LIMA. T. C. S; MIOTO, R. C. T. Procedimentos metodológicos na construção do conhecimento científico: a pesquisa bibliográfica. Rev. Katál, Florianópolis, v. 10 p. 37-45 2007. Número especial.

LOBO, L. F. Os infames da história: pobres, escravos e deficientes no Brasil. Rio de Janeiro; Lamparina: 2008.

MONARCHA. C. Lourenço Filho e a organização da psicologia aplicada à educação: São Paulo, 1922-1933. Brasília, DF: Inep/MEC, 2001.

MONARCHA. C. Sobre Clemente Quaglio (1872-1948): notas de pesquisa Patrono da Cadeira n 31 "Clemente Quaglio". Boletim Academia Paulista de Psicologia - Ano XXVII, n² 2/07: 25-34. 
YVES. J. Désiré Magloire Bourneville : rendre leur humanité aux enfants idiots. Reliance, vol.24, n. 2 p. 144-148. Disponível em https://www.cairn.info/revue-reliance-2007-2-page-144. htm. Acesso em: 18 set. 2018.

OUVRIER-BONNAZ. R. Le laboratoire de pédagogie expérimentale de la Grange-auxBelles : Préoccupation sociale et question scientifique chez Alfred Binet. Revue généraliste de recherche en education et formation. Recherches \& Educations, 5, 2011, p. 131-147.

PATTO, M. H. S. Para uma crítica da razão psicométrica. In: Mutações do cativeiro. São Paulo, EDUSP: 2000.

PESOTTI, I. Deficiência Mental: da superstição à ciência. São Paulo, EDUSP: 1984.

PLETSCH, M. D.; PAIVA, C. Por que as escolas continuam "laudando" alunos com deficiência intelectual? In: Revista Educação Especial, v. 31, p. 1039-1053, 2018.

SCHNEIDER, D. Alunos excepcionais: um estudo de caso de desvio. In: VELHO, G. (org.). Desvio e divergência - uma crítica da patologia social. $8^{\circ}$ ed., Rio de Janeiro: Editora Jorge Zahar, 2003.

WANDERBROOCK JUNIOR. D. A Educação sob medida: os testes psicológicos e o higienismo no Brasil (1914-45). EDUEM: 2009. 
$1 \quad 0$ artigo integra parte das discussões realizadas no estágio de pós-doutorado da primeira autora, sob a supervisão da segunda.

2 Nesse texto utilizaremos os termos anormal/anormalidade, debilidade/débeis, deficiência mental/ deficiência intelectual, entre outros, dependendo do momento histórico discutido no texto.

3 Outros estudiosos da antiguidade como Platão (427 a 347 a.c), Santo Agostinho (354 a 430 d.c) já discutiam a inteligência.

4 Médico especialista em doenças mentais e tratava os chamados "alienados mentais".

$5 \quad$ No fim do século XVIII, utilizou-se a expressão "tratamento moral" para se referir a uma abordagem na qual o paciente era tratado com base em princípios filosóficos e morais correntes. Para mais Esclarecimentos sobre alienistas e tratamento moral consultar o texto: A construção social da pessoa e a psiquiatria: do alienismo a nova psiquiatria de autoria de Ana Teresa Venâncio. 